\title{
Correction to: Small-scale rearing of the black soldier fly, Hermetia illucens (Diptera: Stratiomyidae), in the laboratory: low-cost and year-round rearing
}

\author{
Satoshi Nakamura ${ }^{1} \cdot$ Ryoko T. Ichiki $^{1} \cdot$ Masami Shimoda $^{2} \cdot$ Shinsuke Morioka $^{1}$
}

Published online: 6 January 2018

(c) The Japanese Society of Applied Entomology and Zoology 2018

\section{Correction to: Appl Entomol Zool (2016) 51:161-166 https://doi.org/10.1007/s13355-015-0376-1}

Unfortunately, the $Y$ axis (no. of clutches laid/cage) of Fig. 2 was published incorrectly in the original publication of the article. The correct version of figure is given below.
The original article can be found online at https://doi.org/10.1007/ s13355-015-0376-1.

Satoshi Nakamura

s.nakamura@affrc.go.jp

1 Japan International Research Center for Agricultural Sciences, Tsukuba, Japan

2 National Institute of Agrobiological Sciences, Tsukuba, Japan

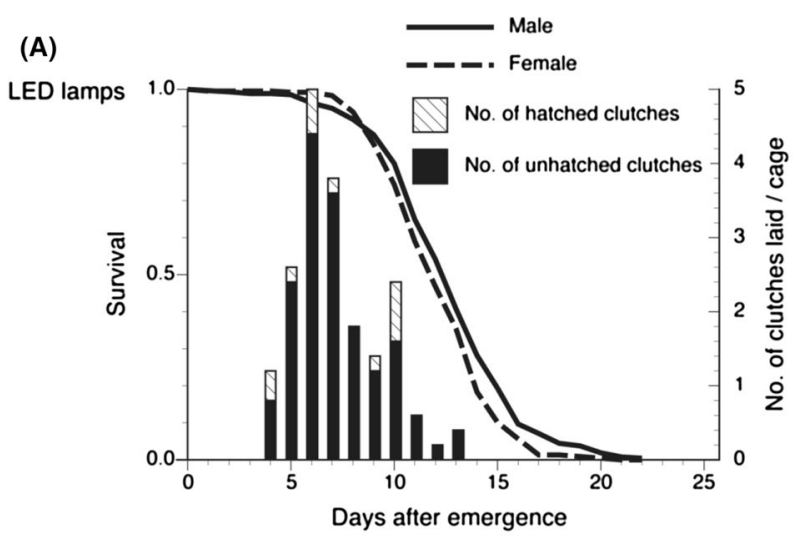

(B)

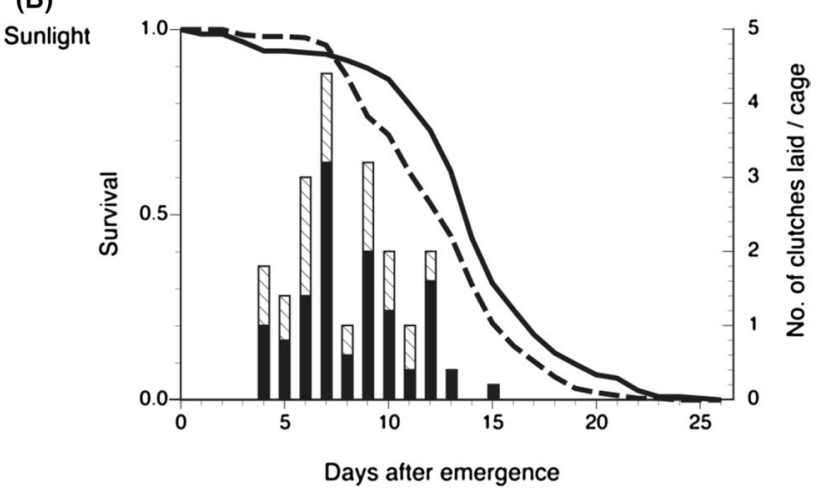

Fig. 2 Survival curves and numbers of clutches laid of Hermetia illucens under artificial lighting supplemented with a LED lamps $(n=5)$ and $\mathbf{b} 2 \mathrm{~h}$ of sunlight per day $(n=5)$ 